\title{
The ways of improving the quality of the secondary education in the Republic of Kazakhstan
}

\author{
Askarbek K. Kousainov, ${ }^{1, *}$ \\ ${ }^{1}$ APS of Kazakhstan, President, Astana, Kazakhstan
}

\begin{abstract}
On the basis of studies of domestic and foreign experience the paper reveals the factors furthering the improvement of the secondary education quality. The complicated system of education consists of subsystems. To improve the quality of education it is necessary to improve the quality of all its components and, in general, the whole educational space. The author states that it is impossible to improve the quality of education without providing the quality of constituent factors for the transition for the 12-year secondary school. For realization of transition for 12-year education all its components, providing its quality in the first form, should be taken into account and realized. The author considers main principle and ways of improving the quality of the secondary education in Kazakhstan.
\end{abstract}

\section{Introduction}

In 2015 Kazakhstan ranks the $42^{\text {nd }}$ place in the rating of global competitiveness having improved its position for 14 standings in comparison with 2006. The nation's leader N.A. Nazarbaev defined a goal for Kazakhstan to join the first thirty competitive world countries. The quality of education should correspond with the level of the leading world countries.

Among the factors defining the competitiveness of Kazakhstan there are the following ones: "Health and primary education" and "Higher education and professional training". Comparatively with 2006 the first figure lowered 7 standings and the second one 9 standings and Kazakhstan ranked, correspondingly, the $93^{\text {rd }}$ and the $60^{\text {th }}$ places.

The quality of education is the basis for the national prosperity and security. To make sure of the appropriateness of the work conducted, many countries in the world taking part in such international research for the quality of education evaluating as PISA, TIMSS and others are able to evaluate the education in their countries in comparison with the others.

In 2007 our country took part in TIMSS 2007 research for the first time. The pupils of the $4^{\text {th }}$ grade took the $5^{\text {th }}$ place in mathematics and the $11^{\text {th }}$ place in natural sciences. In 2011 the pupils of the $4^{\text {th }}$ grade took the $27^{\text {th }}$ and the $32^{\text {nd }}$ places correspondingly worsening their performance for 22 and 21 standings. The pupils of the $8^{\text {th }}$ grade took the $17^{\text {th }}$ and the $20^{\text {th }}$ places, i.e. those children who studied in the $4^{\text {th }}$ grade in 2007 worsened their results studying in the $8^{\text {th }}$ grade for 12 and 9 standings correspondingly.

Kazakhstan took part in PISA in 2009 and 2012. At that time 15 -year old students took the $59^{\text {th }}$ and $63^{\text {rd }}$ places in reading literacy, the $53^{\text {rd }}$ and $49^{\text {th }}$ places in mathematical literacy and the $58^{\text {th }}$ and $52^{\text {nd }}$ places in scientific literacy, i.e. they improved their performance in mathematical and scientific literacy. However, these results appeared to be lower than the average performance in OECD countries.

We focused our efforts in studying the problems of the improvement of the secondary education quality. At first, scrutinizing PISA, TIMSS and PIRLS results during the last 10-12 years we ascertained the leading countries where the students consistently showed high results, and factors ensuring their successful performance [1].

We also studied researches carried out in other countries. The employees from McKinsey\&Company M.Barber, M.Murshed, Ch.Chijoke and others to answer the questions: "How to achieve steadily high quality of education at schools?" and "How the best systems of school education keep on improving?" studied in details the systems of education of 45 countries [2, 3].

Our scientists also scrutinized the domestic experience of Kazakhstan during the period of independence and on the basis of this research we made a conclusion that the system of education is a complex system, which like many other complex systems includes many components (subsystems) and itself is a part of educational space.

To improve the quality of education it is necessary to improve the quality of its components. According to our definition, all educational space is the component itself: standards and curricula; academic literature; teaching staff (their professional skills); monitoring of education; moral and patriotic education; scientific research in the sphere of education; the system of

\footnotetext{
Corresponding author: apnkaz@mail.ru
} 
management; material and technical base.

During the transition to the 12-year secondary education it is impossible to improve the quality of education without providing for the quality of all components. It is necessary to carry out systemic and efficient work for improvement of the quality of all the components beginning with the first grade. The same work should be carried out in the second and in the following grades.

Basing upon the studies of domestic and best foreign practice to improve the quality of the components of education the following tasks should be solved.

\section{Improving the quality of standards and curricula.}

At present schooling is realized basing on centric paradigm. To improve the quality of education during the transition to the 12-year education it is necessary to realize education on the base of the outcomes-oriented paradigm while forming the learners' competences. Its aim consists in the following: each student should acquire knowledge connecting it with the real life situation. Let's look at an example. Having studied Ohm's law the pupil should know what to do in the situation when the lamp permanently burns out using this law. This example demonstrates that we should be able to use knowledge obtained at school in the real life situation. It is a very difficult problem. During many years it is being solved in such countries like Japan, South Korea, Singapore and Finland where the secondary education is of a high quality.

In general, we should not allow children to be overburdened with the learning of difficult subjects from the early age, as it negatively influences their psychological, physiological and cognitive development as well as it discourages them to acquire knowledge. It is important to pay more attention to study the subjects forming their moral qualities favoring their intellectual development.

\section{Improving the quality of academic literature.}

The main shortcoming in writing the academic literature is the absence of a unified author group which works creates textbooks and teaching materials complexes for a certain subject for all grades of education. When pupils of different classes study the same subject with textbooks of different authors, they cannot get a quality education. It is necessary to organize unified author groups for the development of a set of textbooks or innovative methodical complexes for a certain subject; to improve practical competenceforming orientation of teaching materials and to increase the proportion of various creative tasks; to realize the technology of interactive education; to form information culture.

Creation of a multimedia tutorial should accompany the writing of a textbook. This multimedia tutorial should include systemically all the necessary materials for the textbook from Internet. It will be very helpful for acquisition of profound knowledge for every academic subject.

During preparation of the academic literature for the first grade of the 12-year secondary school it is desirable to solve the problems related to the academic literature of the whole primary school. Only in this case the quality of education can improve at the primary school.

\section{Improvement of the quality for professional development of the school personnel.}

The work for the improvement of professional development of the school staff can be carried out in two ways: improvement of the quality for teachers' training and increasing the competence of teachers' staff.

Improvement of the quality for professional development of teachers is a large autonomous program. We face the problem of, first of all, improving the professional skills of teachers who will work in the first grade of the 12-year school. It is a known fact that, due to a number of objective and subjective reasons, professional competency of the teaching staff in Kazakhstan has degraded.

The researches carried out by $\mathrm{M}$. Barber and $\mathrm{M}$. Murshed from McKinsey\&Company showed that if the 8 -year old pupils of moderate abilities are taught by different teachers, one of them having high professional skills while another one is of a low qualification, within three years these pupils will show outcomes differing 53\%. Schoolchildren taught by highly professional teachers develop three times quicker than those who are taught by the teachers of a low qualification. Pupils showing poor performance at the age of 11 have only $25 \%$ chances to obtain the necessary knowledge according to the standard requirements for the age of 14 .

It is proved that the quality of education cannot be higher than the quality of teachers working at school, and the only way to improve the learning outcomes is to improve teaching. It is proved that an incorrect personnel solution can lead to forty years of bad teaching. That is why in the countries, which are leading in primary education sphere, holders of a master's degree teach at primary school, and they are trained as if surgeons before surgical intervention.

At first, it is necessary to increase the competency of all teachers who work at the first grade according to the new content of education. Only in this case the quality of education of the $1^{\text {st }}$ grade pupils will be improved. If next year these teachers work in the $2^{\text {nd }}$ grade, it is necessary to improve competency of teachers for the new first grade. In general, it is necessary that teacher with high professional skills work according to the programs with new content of education. Only in the case of such systemic work it is 
possible to improve the quality of education.

In the countries-leaders in the field of primary education exemplary lesson plans and teaching materials are developed to direct and facilitate the work of teachers in improving the quality of lessons on the basis of Public contract. For those who really want to work as a teacher the authorities support improving the quality of their lessons without excessive criticism and humiliation but with special care. We should take into account this positive experience.

\section{Improving the quality of educational monitoring.}

It is a known fact that it is impossible to improve what was not measured. That is why great attention is paid to the creation of the system of the education quality monitoring in the leading countries. For instance, the USA spends $20-25 \%$ of all expenditures for the improving the quality of education to develop the system of educational monitoring. To improve the quality of a certain thing it is necessary to evaluate it, to identify its disadvantages and to determine what to do. The system of education follows the same principle.

International studies like PISA, TIMSS, PIRLS and others are based on application of the advanced methods for educational evaluation. In Kazakhstan the system of educational monitoring is not developed. There is no unified set of instruments for education quality evaluation; the science of educational evaluation is not developed as well as its qualimetric methods and testology for education quality evaluation.

To realize high-quality transition to the 12-year education it is necessary to create tools for education quality evaluation of academic subjects for the first grade and efficient assessment of learning outcomes in different subjects. It is a very complicated problem, but until it is solved we are not able to assess objectively what we do in this sphere.

\section{Improving the quality of moral and patriotic personal upbringing.}

Countries leading in the sphere of education pay special attention to the upbringing of a creative, morally and intellectually developed personality who can keep and increase greatly spiritual heritage of generations, determine national priorities. In these countries about $50 \%$ of academic load in primary school curriculum is connected with subjects forming spiritual and moral values and physical qualities of pupils.

The Great Thinker M. Montaigne emphasized that the greatest narrow-mindedness is teaching children the science about stars earlier than the science about their own impulses [4]. Japanese Emperor Meiji wrote that people should first cultivate spirituality and adhere to moral principles and then they could learn various subjects according to their abilities [5].
Historically the ideas on education always based upon the strong spiritual and moral values in Kazakhstan. Original spiritual philosophy of the Kazakhs is filled with love for their native land, wisdom, tolerance. However, unfortunately, due to objective and subjective reasons, many values were lost, forgotten and indoctrinated. In recent years sufficient attention is not given to the moral education of youth. The main emphasis is laid to the acquisition of learning outcomes: successful results of exams and good arks.

In our opinion, it is important to instill in students high moral and patriotic feelings, necessary to realization the National idea of Kazakhstan President N.A. Nazarbayev "Мәңгілік ел”, such as respect for parents, love for the Motherland, knowing and development of culture and history, preserving the country's unity, tolerance and peoples' friendship, diligence, keeping health and environment, mastering the Kazakh language and foreign languages, getting a high-quality education. This idea should be realized in school standards, curricula and the academic literature.

\section{Improving the quality of scientific research in the sphere of education.}

To improve the quality of the secondary education it is necessary to carry out research basing on the objectives, as the level of the development of the system quality depends on the level of achievements of the science of pedagogy. In Kazakhstan fundamental and applied scientific researches are carried out for the examining the problems in the sphere of education. It is necessary to pay more attention to the study of the problems of transition to the 12-year education and improving its quality, development of standards and curricula, realizing the transition for student-centered paradigm with dominating competence-based approach, creation of scientific and practical foundation for the development of innovative education methodical complex, creation of the system for education quality evaluation.

Basing on these researches scientifically substantiated proposals for their solutions and implementation should be prepared. Besides, scientific research and practical work should be carried out in advance for their results to be used timely in real practice.

\section{Improving the quality of the management system.}

The efficiency of the education quality management system depends on the ensuring continuity in the management of the education system, from the management of the authorized body to the certain school management. To improve the education quality for the transition to the 12-year education all the institutions of the management system should work jointly. 
The main work for the improvement of the education quality is realized at school. However, the high-quality performance depends directly on the activity of the principal who becomes a key figure in ensuring the quality of education. In the leading countries in the sphere of education only experienced director of studies is appointed as a school principal, the best school counselor can become a school director of studies and the best teacher can be appointed as a school counselor. In our opinion, we can adopt these countries experience even when the principal is appointed, at that special attention should be paid to his/her pedagogical professionalism and competency.

\section{Improving the quality of material and technical base.}

The government of Kazakhstan pays great attention to the improving of material and technical base of the system of education as a whole and the secondary education in particular. It is necessary to improve the level of logistics for secondary schools, especially for ungraded schools in rural areas.

\section{Conclusion.}

At his time Director of the International Institute for Educational Planning Paul Bélanger noted that the experience of many countries showed that the main reason for complexity of educational process consisted not only in financial support, but in the difficulties which we could not overcome with investments only [6]. His predecessor Philip H. Coombs specified this idea stating that to cope with crisis every system of education should be able to have ideas, courage, determination, the ability of critical self-assessment combined with the desire to change [7].
To improve the quality of all the component of the education system of Kazakhstan it is necessary to mobilize and to ensure the efficient performance of a large team of scientists, teachers and parents, scientific research organizations and educational institutions, textbook authors and publishers, the teaching staff and the public, i.e. the whole educational space.

\section{References}

1. A. Kousainov, Kachestvo obrazovaniya $v$ mire $i v$ Kazahstane (IET, Moscow, 2014) [In Rus]

2. M.Barber, and M.Murshed, Consistently high performance: Lessons from the world's top performing school systems (McKinsey\&Company. June 2007).

3. M.Barber, M.Murshed, and Ch.Chijioke, How the world's most improved school system keep getting better (McKinsey\&Company. June 2007).

4. M. Montaigne, Of the education of children (Trans. Charles Cotton, 1580), available online: URL http://essays.quotidiana.org/montaigne/education_of c hildren/ (accessed on: 04.03.2014).

5. D. Irokawa, The Culture of the Meiji Period (Princeton, 1988)

6. W.D. Haddad, Education Policy-planning Process: An Applied Framework (UNESCO-IIEP, 1995)

7. The World Educational Crisis (Oxford University Press, 1968) 